\title{
SISTEM INFORMASI KEPADATAN LALU LINTAS BERBASIS RASPBERRY PI PC BOARD
}

\author{
Fitria Rahmadina, Zaini \\ Jurusan Teknik Elektro, Fakultas Teknik, Universitas Andalas \\ Jln. Kampus Limau Manis Kota Padang 25163 INDONESIA \\ *Corresponding author, e-mail : fitria.rahmadina21@gmail.com
}

\begin{abstract}
Abstrak - Seiring dengan meningkatnya rutinitas masyarakat pada era globalisasi, tingkat pertumbuhan jalan dan tingkat pertumbuhan kendaraan menjadi tidak seimbang sehingga menimbulkan kemacetan lalu lintas. Pemanfaatan mini komputer dapat membantu dalam memonitoring kepadatan lalu lintas. Sistem ini mengimplementasikan Raspberry Pi yang dilengkapi kamera untuk mengambil gambar dari keadaan jalan raya. Sistem diletakkan di ketinggian dan sudut tertentu sehingga dapat memantau keadaan lalu lintas. Penelitian ini bertujuan membangun sistem informasi menggunakan computer vision dengan teknik background subtraction. Gambar diolah sehingga menghasilkan data dari perhitungan contour feature berupa kepadatan lalu lintas yang selanjutnya akan dikirim ke server. Sehingga pada akhirnya dengan sistem ini informasi data kepadatan lalu lintas secara langsung dapat diketahui dengan akurasi sebesar $87,6 \%$.
\end{abstract}

Kata Kunci : Raspberry Pi, background subtraction, kepadatan lalu lintas.

\begin{abstract}
Due to increasing routine society in the era of globalization, the growth rate of the road and the vehicle becomes unbalanced so that cause traffic jams. Utilization of mini computers can help in the monitor of traffic density. This system implements Raspberry Pi equipped cameras to take pictures of the density of highways. The system is placed in a certain angle and height so that it can monitor the state of traffic. This research aims to build information systems using computer vision with background subtraction model. Image processed to produce data from calculation of contour feature such as traffic density which will be sent to the server. So in the end with this system information data traffic density directly can be known with accuracy of $87,6 \%$.
\end{abstract}

Keywords : Raspberry Pi, background subtraction, traffic density

Copyright $(2016$ JNTE. All rights reserved

\section{PENDAHULUAN}

Perjalanan yang lancar dan menyenangkan tentu sebuah dambaan yang indah bagi semua orang. Dalam kenyataanya sering kita terjebak dalam kemacetan di jalan raya sehingga menimbulkan berbagai macam permasalahan yang tentu dapat merusak suasana.

Berdasarkan data Pusat Statistik kota Padang, terjadinya peningkatan jumlah penduduk sebanyak 111.978 semenjak tahun 2003 hingga akhir tahun 2013. Pada 2003 tercatat sebanyak 764.700 jiwa dan pada akhir tahun 2013 mencapai 876.678 jiwa. Kondisi tersebut secara tidak langsung akan menambah sarana transportasi dalam mobilitas kehidupan yang semakin tinggi. Bertambahnya jenis kendaraan seperti mobil pribadi dan angkutan masal menimbulkan kepadatan lalu lintas.
Permasalahan kemacetan lalu lintas akan menimbulkan dampak negatif bagi masyarakat, yaitu merugikan waktu dan pemborosan energi bahan bakar.

Dalam informasi kepadatan lalu lintas dibutuhkan teknik yang mampu membantu dalam memonitoring kepadatan lalu lintas. Informasi dapat diekstrak melalui gambar dengan mengenali objek menggunakan computer vision dengan teknik background subtraction. Background subtraction merupakan pendekatan yang digunakan untuk mendeteksi objek yang begerak dari kamera statis[6].

Penggunaan komputer dengan daya yang besar dan ukuran yang besar, tentunya kurang efektif bila digunakan sebagai pengontrol jarak jauh. Karena itulah penggunaan mini PC dapat menggantikan peran komputer. Penerapan sistem pengendalian untuk konten multimedia 
dapat dilakukan dengan platform Raspberry Pi [3]. Pemilihan alat ini dikarenakan kinerjanya yang baik, mendukung berbagai perangkat keras dan harga yang terjangkau bagi masyarakat luas[4].

\section{TINJAUAN PUSTAKA}

\subsection{Intelligent Transportation System (ITS)}

Intelligent Transporation System merupakan sistem cerdas dalam hal transportasi untuk membantu pengguna mendapatkan kemudahan dalam informasi. Informasi kepadatan lalu lintas secara real-time mempunyai peran yang penting dalam pembentukan sebuah Intelligent Transportation System[1]. Dalam pengoperasian sebuah ITS, prediksi lalu lintas yang akurat merupakan salah satu langkah yang penting[2]. ITS yang baik dapat memberikan kemudahan pada user dalam merencanakan perjalanannya. ITS telah diterapkan di kota maju seperti Jepang, Amerika Serikat, Singapura, Korea Selatan dan Eropa sebagai solusi lalu lintas [5].

\subsection{Raspberry Pi}

Raspberry Pi merupakan sebuah komputer seukuran kartu ATM yang dapat digunakan seperti sebuah Personal Computer (PC). Perangkat mini ini dikembangkan pertama kali oleh Raspberry Pi Foundation untuk menarik minat pelajar yang ingin mempelajari bahasa pemrograman komputer.

Raspberry $\mathrm{Pi}$ membutuhkan operating system agar dapat digunakan. OS yang digunakan Raspberry Pi merupakan varian dari Linux. Sebagai pengganti hardisk pada komputer, Raspberry Pi menggunakan SD Card. Raspberry $\mathrm{Pi}$ dirilis dengan lisensi open sourcehardware sehingga telah dipergunakan untuk berbagai fungsi, diantaranya media centre, networked compute, take pictures and record videos serta sebagai web server. Salah satu pemanfaatan Raspberry Pi dapat membangun sistem monitoring yang inovatif dan cerdas [7].

\subsection{Background subtraction}

Pengolahan citra adalah pemrosesan citra menggunakan komputer menjadi citra yang kualitasnya lebih baik dan sesuai dengan keinginan pemakai. Tujuannya adalah memperbaiki citra agar mudah diinterpretasikan oleh manusia atau komputer. Pengolahan citra mempunyai aplikasi yang sangat luas dalam berbagai bidang kehidupan, salah satunya sebagai komunikasi data.

Informasi dapat yang diinginkan dapat diperoleh dengan melakukan beberapa teknik dan fitur tertentu dalam pengolahan citra[8]. Salah satu teknik pada pengolahan citra adalah background subtraction. Background suntraction merupakan teknik pengolahan citra dan computer vision yang bertujuan untuk mendeteksi objek dari suatu citra latar belakang. Proses deteksi objek bergerak dengan metode ini didasarkan pada perbedaan antara citra background dan citra berobjek. Untuk memfokuskan pada bentuk objek digunakan operasi morfologi yang diklasifikasikan dalam beberapa bagian :

1. Pencarian batas atau contour, untuk menentukan batas atau contour dari segmen obyek

2. Dilasi, untuk memperbesar ukuran segmen obyek dengan menambah lapisan di sekeliling obyek

3. Erosi untuk memperkecil ukuran segmen objek dengan mengikis sekeliling obyek

4. Penutupan (closing), merupakan kombinasi antara operasi dilasi dan erosi yang dilakukan secara berurutan.

5. Pembukaan (opening), merupakan kombinasi antara operasi erosi dan dilasi yang dilakukan secara berurutan.

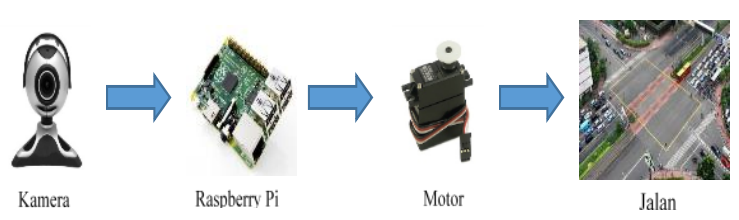

Gambar 2. Proses pengambilan gambar

\subsection{Python}

Python dikembangkan oleh Guido van Rossum pada tahun 1990 di CWI, Amsterdam sebagai kelanjutan dari bahasa pemrograman ABC. Saat ini pengembangan Python terus dilakukan oleh sekumpulan pemrogram yang dikoordinir Guido dan Python Software Foundation. Python merupakan salah satu produk yang opensource, free, dan multiplatform. Pada kebanyakan sistem operasi Linux, bahasa pemrograman ini menjadi standarisasi untuk disertakan dalam paket distribusinya. Saat ini kode python dapat 
dijalankan pada sistem berbasis: Linux/Unix, Windows, Mac OS X, OS/2, Amiga, Palm, Symbian (untuk produk-produk Nokia).

\section{METODE PENELITIAN}

Perancangan sistem diilustrasikan pada Gambar 1.

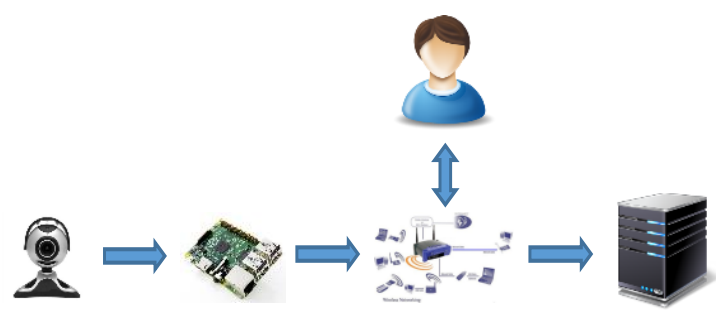

Gambar 1. Rancangan sistem informasi lalu lintas berbasis Raspberry $\mathrm{Pi}$

1. Perancangan Raspberry Pi dengan kamera Sistem diletakkan di ketinggian dan sudut tertentu jalan raya sehingga dapat memantau keadaan lalu lintas. Proses pengambilan gambar diilustrasikan pada Gambar 2 berikut.

2. Proses Pembacaan Data dengan Background Substraction

Setelah kamera menangkap citra (gambar), dilakukan proses background subtraction (pengurangan citra latar belakang) untuk untuk mensegmentasi objek sebagai latar depan dari sebuah latar belakang pada gambar. Tahapan perolehan objek menggunakan background subtraction dijelaskan pada Gambar 3.
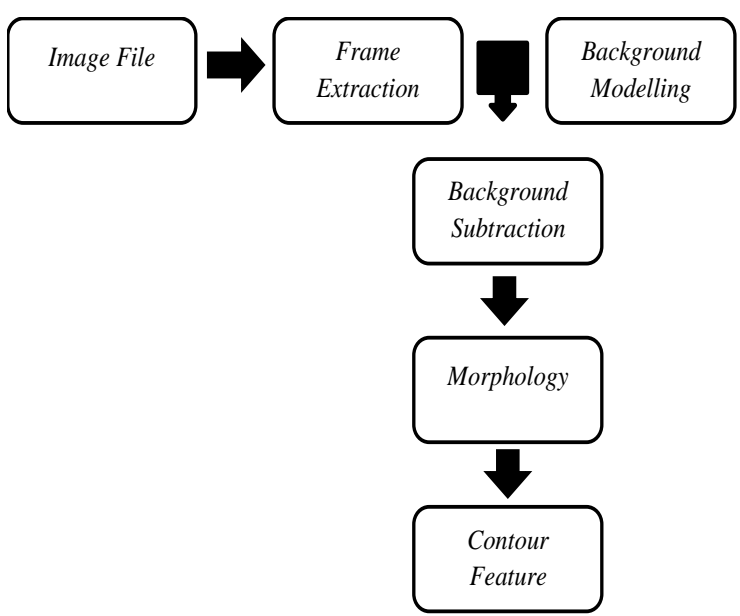

Gambar 2. Tahapan perolehan objek menggunakan background subtraction
Objek yang sudah dipisahkan dari latar belakangnya kemudian dapat dilakukan proses klasifikasi untuk menentukan apakah objek termasuk dalam jenis kendaraan atau tidak. Dalam hal ini dilakukan pengklasifikasian objek berdasarkan ukuran.

3. Pengiriman data melalui jaringan broadband dan $3 \mathrm{G}$ ke server dengan IP publik dan menampilkannya dengan sistem berbasis website.

\section{HASIL DAN PEMBAHASAN}

Penelitian ini menggunakan data situasi lalu lintas yang diambil di Jl. Sawahan. Hasil pemantauan dan pembacaan data dari Raspberry Pi ini ditampilkan dalam bentuk website yang dihubungkan ke server untuk memudahkan pengaksesan dari jarak jauh.

\subsection{Hasil Pengujian Sistem}

Kamera yang dihubungkan dengan Rapberry Pi tipe B+ diletakkan di suatu bangunan dengan ketinggian tertentu agar dapat mengambil gambar secara utuh. Hasil pembacaan data dari jalan raya yang diperoleh diolah menggunakan background subtraction dengan algoritma Gaussian Mixture - based Background / Foreground Segmentation.

Penentuan citra latar belakang (background image) dilakukan secara manual. Citra latar belakang yang ditangkap merupakan kondisi jalan raya saat lingkungan dalam keadaan diam atau tidak ada objek yang bergerak. Gambar 4 merupakan citra model latar belakang (backgorund image) yang ditentukan dalam penelitian ini.

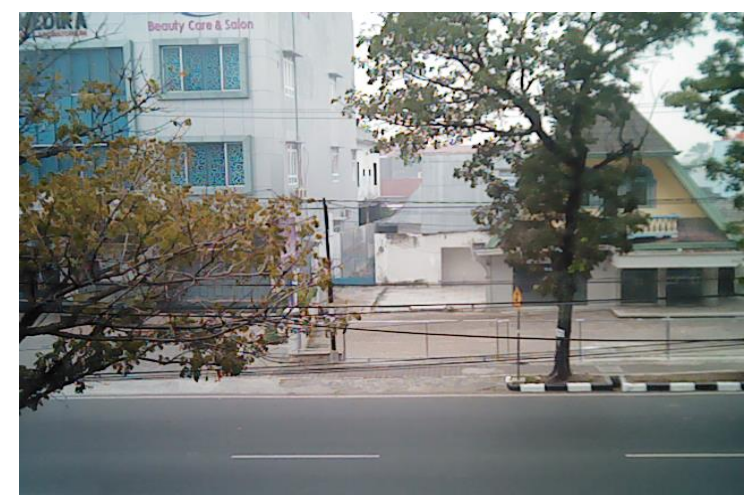

Gambar 3. Citra latar belakang dari background subtraction 


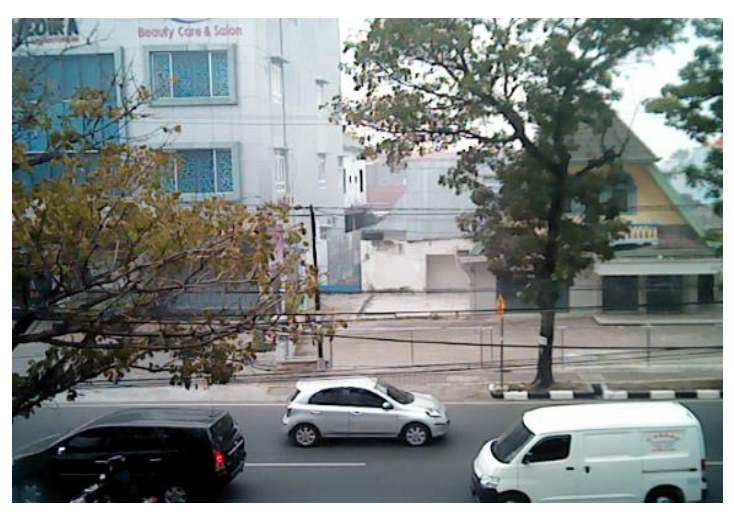

Gambar 4. Hasil citra dengan objek bergerak

Pemrosesan background subtraction dilakukan pada background image untuk mendeteksi objek yang bergerak. Hasil objek yang bergerak dapat dilihat pada Gambar 5 . Untuk menghilangkan noise pada citra digunakan operasi morfologi dengan metode opening. Hasil sebelum dan setelah operasi morfologi yang dilakukan terlihat pada Gambar 6 dan Gambar 7.

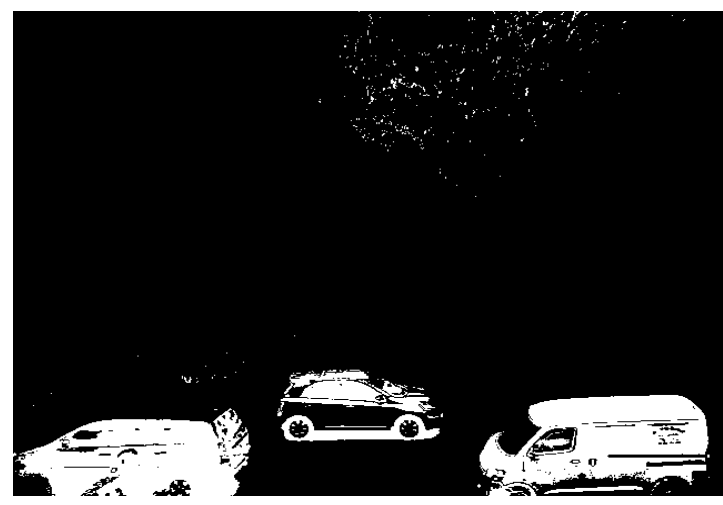

Gambar 5. Citra hasil sebelum operasi morfologi

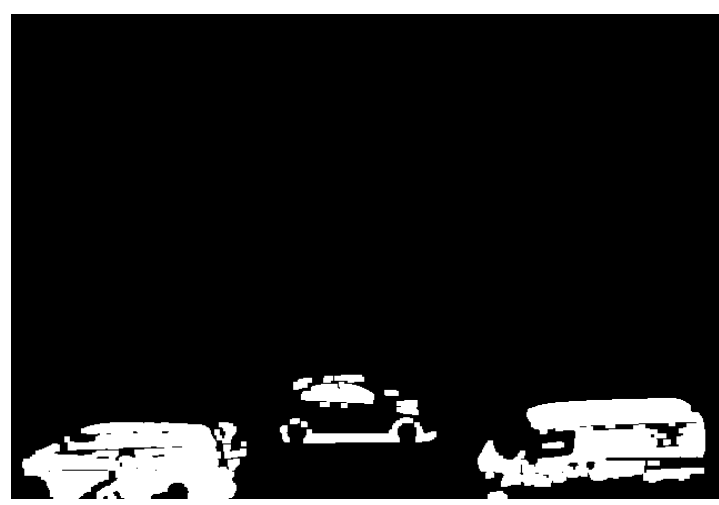

Gambar 6. Hasil citra sesudah operasi morfologi
Program hanya akan menghitung jumlah kendaraan roda empat yang melewati suatu area sehingga volume kendaraan dapat terpantau. Pada penelitian ini kendaraan roda empat memiliki contour lebih besar daripada 800 . Pengambilan data hanya dapat dilakukan ketika area pengambilan memiliki cahaya yang cukup.

Pengambilan data pada saat cuaca dengan curah hujan sedang, tidak memberikan pengaruh pada hasil perhitungan jumlah kendaraan. Hal ini disebabkan noise yang ditimbulkan oleh hujan pada gambar memiliki ukuran contour yang lebih kecil daripada ukuran contour kendaraan roda empat. Menemukan contour seperti menemukan objek putih yang terdapat pada background hitam. Contour setiap objek yang ada pada citra tidak sama.

\subsection{Evaluasi}

Evaluasi dilakukan dengan penelitian sebanyak 20 sampel secara subjektif dari pengguna dengan menghitung persentase jumlah kendaraan yang melewati suatu area dan jumlah kendaraan yang terhitung dari pengolahan menggunakan Raspberry Pi. Hasil menunjukkan nilai sebesar $81 \%$.

$$
\begin{aligned}
& \text { Evaluasi } \\
& =\frac{\text { jumlah kendaraan terhitung }}{\text { jumlah kendaraan sebenarnya }}
\end{aligned}
$$

\section{KESIMPULAN DAN SARAN}

\subsection{Simpulan}

Penelitian ini membangun sistem informasi lalu lintas berupa volume kendaraan yang diolah menggunakan Raspberry $\mathrm{Pi}$ dan kamera menggunakan metode background subtraction . Hasil pemodelan ini memiliki tingkat akurasi dengan nilai $87,6 \%$.

\section{DAFTAR PUSTAKA}

[1] W. H. Lee, S. S. Tseng, W.Y. Shieh, "Collaborative Real-Time Traffic Information Generation and Sharing Framework for The Intelligent Transportation System", Information Sciences vol.180 (2009) pp.62-70, September. 2009.

[2] A. Costanzo, "An arduino based System Provided with GPS/GPRS Shield for Real 
Time Monitoring of Traffic Flows", IEEE $14^{\text {th }}$ International Conference (2013) pp.15, Oktober. 2013.

[3] V. M Ionescu, "Control System for Video Advertising based on Raspberry Pi", IEEE International Conference $12^{\text {th }}$ (2013) pp.1-4, September 2013.

[4] M. Kochlan, M. Hodon, L. Cechovic, J. Kapitulik, M. Jurecka, "WSN for Traffic Monitoring using Raspberry Pi Board", IEEE Federated Conference on 2014, pp.1023-1026. September 2014.

[5] S. Ezell, "Intelligent Transport System (Explaining International IT Application Leadership)", ITIF The Information Technology \& Innovation Foundation. Januari 2010.

[6] M. Piccaerdi, "Background Subtraction Techniques: a Review", IEEE International Conference on Sytems, Man and Cybernetics on 2004. Pp. 3099-3104. 2014.

[7] S.S. Lagu, "Raspberry Pi for Automation of Water Treatment Plant", IEEE International Conference on 2014, pp.1999-2003. September 2014.

[8] R.F. Gusa, "Pengolahan Citra Digital untuk Menghitung Luas Daerah Bekas Penambangan Timah", Jurnal Nasional Teknik Elektro, vol.2, no.2, ISSN: 23022949. September 2013

\section{Biodata Penulis}

Fitria Rahmadina, lahir di Bukittinggi tanggal 21 Maret 1992. Menerima gelar sarjana di Fakultas MIPA Institut Pertanian Bogor pada tahun 2013. Sekarang tengah menempuh pendidikan jenjang Magister Teknik Elektro Universitas Andalas Padang. 